\title{
Genetic factors and breast cancer laterality
}

This article was published in the following Dove Press journal:

Cancer Management and Research

16 April 2014

Number of times this article has been viewed

\section{Magid H Amer}

Department of Medicine, St Rita's Medical Center, Lima, OH, USA
Correspondence: Magid H Amer 825 West Market Street, Suite 203, Lima, OH 45805, USA

Tel + I 6144990296

Fax + I 6144484499

Email magidamer@email.com
Background: Women are more likely to develop cancer in the left breast than the right. Such laterality may influence subsequent management, especially in elderly patients with heart disease who may require radiation therapy. The purpose of this study was to explore possible factors for such cancer laterality.

Methods: In this work, clinical data for consecutive patients with histologically confirmed breast cancer were reviewed, with emphasis on clinical presentation and family history.

Results: Between 2005 and 2012, 687 patients with breast cancer were seen. Two women with incomplete data and eleven men were excluded. In total, $343(50.9 \%)$ patients presented with left breast cancer, 311 (46.1\%) with right breast cancer, and $20(3.0 \%)$ with simultaneous bilateral malignancy. There were no significant differences between the three groups, especially in regards to clinical presentation and tumor characteristics. A total of $622(92.3 \%)$ patients had unilateral primary, 20 (3.0\%) had simultaneous bilateral, and 32 (4.7\%) had metachronous primary breast cancer with subsequent contralateral breast cancer after 7.5-236 months. The worst 10-year survival was for bilateral simultaneous (18\%) compared with unilateral (28\%) and metachronous primaries (90\%). There were no differences in survival in relation to breast cancer laterality, handedness, and presence or absence of a family history of cancer. There were significant similarities between patients and first-degree relatives in regards to breast cancer laterality, namely same breast (30/66, 45.5\%), opposite breast $(9 / 66,13.6 \%)$, and bilateral cancer $(27 / 66,40.9, P=0.01163)$. This was more evident among patients and their sisters $(17 / 32$, $53.1 \%)$ or mothers $(11 / 27,40.7 \%, P=0.0689)$. There were also close similarities in relation to age at initial diagnosis of cancer for patients and their first-degree relatives for age differences of $\leq 5$ years $(48 / 166,28.9 \%), 6-10$ years $(34 / 166,20.5 \%)$, and $>11$ years $(84 / 166,50.6 \%$, $P=0.12065)$.

Conclusion: High similarities between patients and their first-degree relatives in regards to cancer laterality and possibly age at initial diagnosis of cancer may suggest an underlying inherited genetic predisposition.

Keywords: breast neoplasms, genetics, left-right determination factors, cerebral factors, dominance, survival analysis

\section{Introduction}

It has been consistently documented that women are somewhat more likely to be diagnosed with left breast cancer than right. ${ }^{1,2}$ Although the excess of left-sided tumors is not large and does not impact overall survival, ${ }^{3}$ it may influence subsequent management, especially in elderly patients with ischemic heart disease. For cases with leftsided implantable devices, such as a pacemaker or defibrillator, that require radiation therapy to the left breast, the implantable devices need to be relocated to the right side 
prior to initiation of radiation therapy. Radiation therapy to the left breast needs to be closely monitored for the risk of long-term post-radiation cardiovascular complications, such as coronary artery occlusion and cerebrovascular thrombosis. Furthermore, the consistency of such an observation in numerous previous publications argues against it being coincidental, and thus may reflect etiological factors not yet recognized or understood.

Interest in the laterality of breast cancer was initially expressed 75 years ago by von Fellenberg, ${ }^{4}$ who found a greater frequency of involvement of the left breast following a review of 986 cases identified by the Swiss Cancer Census for the years 1933-1935. Although the left predominance has since been repeatedly noted, no satisfactory explanation has been provided. ${ }^{1}$ The present study assesses laterality in a cohort of consecutive patients with breast cancer and explores the factors that may have contributed to such an observation.

\section{Materials and methods Data collection and grouping}

The medical records of breast cancer patients previously seen and closely followed by the author were retrospectively reviewed, with special emphasis on clinical presentation, tumor characteristics, family history, and subsequent survival. The study included all consecutive adult patients with histologically confirmed breast cancer, either invasive or carcinoma in situ. All data collected were deidentified to comply with the Health Information Protection Act. The study was approved by the institutional review board at St Rita's Medical Center.

Patient age was estimated based on that at the time of the initial diagnosis of cancer. Elderly patients were defined as being aged $\geq 65$ years. Ethnic background was categorized as Caucasian, Native American Indian (from both parents), African American, or others. Smoking status was categorized as smoker and nonsmoker. Body mass index $\left(\mathrm{kg} / \mathrm{m}^{2}\right)$ was categorized as underweight $(<18.4)$, normal (18.5-24.9), or overweight $(>25)$. Patients were questioned about any previous history of thromboembolic events, and closely followed for such a possibility. Patients were asked about their handedness. For simplicity, left-handed and ambidextrous individuals were collectively referred to as non-right-handed persons.

Primary tumor laterality was classified as left side, right side, or bilateral. Tumor blocks for each case were studied using immunohistochemical staining for estrogen and progesterone receptors and human epidermal growth factor receptor 2 (HER2/neu) scoring or the fluorescent in situ hybridization technique, using established methods. Because of the small number of events, hormone receptor status was classified as a two-level variable, namely estrogen receptor-positive and/or progesterone receptor-positive, and both estrogen receptor-negative and progesterone receptornegative. Presence or absence of lymphovascular invasion was determined in some patients. Stage of disease was defined according to the American Joint Committee of Cancer Staging Classification (Seventh Edition, 2010). ${ }^{5}$

Multiple cancers were defined as two or more primary cancers occurring in an individual that were not an extension, recurrence, or metastasis. Based on the chronology of presentation, they were categorized as synchronous or metachronous primaries. Synchronous primaries were defined as malignancies presenting within 6 months of diagnosis of the index tumor (initial malignancy). This includes simultaneous primaries that were diagnosed at the same time during the staging workup of the first malignancy. Metachronous primaries were considered to be those presenting more than 6 months following the diagnosis of the index tumor. All patients with simultaneous bilateral breast cancer were considered to have a single primary if they shared the same histological diagnosis. For patients with multiple malignancies, the date of the first primary diagnosis was considered the date of initial cancer diagnosis.

Patients were questioned about their family history of cancer, and in particular, the occurrence of breast or ovarian cancers among their first-degree relatives (biological mother, father, sister, brother, son, and daughters) and second-degree relatives (paternal or maternal uncles, aunts, grandmother, and grandfather). They were also asked to provide information regarding the type of cancer, age at initial diagnosis, tumor laterality, and any other hereditary disorders. All patients were treated according to standard guidelines adopted from the recommendations published by the National Comprehensive Cancer Network. Follow-up times were calculated from the date of the initial clinic visit until the earliest event of interest, ie, death or the last date of contact as of the end of December 2012, and were expressed in months. Overall survival was calculated from the date of the initial histological diagnosis of cancer until the day of death or if the patient was confirmed to be alive by the end of December 2012, and was measured in years.

\section{Statistical methods}

Differences between categorical groups were tested using Pearson's chi-squared test. For data with small numbers, 
Fisher's exact test was used. Analysis of variance was used to analyze the differences between means of continuous variables, such as age in years, and expressed as the mean \pm standard deviation. The chi-squared test was used to examine the relationship between qualitative variables. Factors influencing survival were estimated by Kaplan-Meier survival analysis, and the log-rank test was used to compare the distribution of survival between groups. In all analyses, a two-sided $P$-value less than 0.05 was considered to be statistically significant. Missing data were deleted from the analysis. The statistical analysis was conducted using Statistica version 10 software (Stat Soft Inc., Tulsa, OK, USA).

\section{Results}

The study included all consecutive patients with breast cancer, ie, 676 women and eleven men, with an age range of 22-96 (median 58.3) years, initially seen or subsequently followed by the author between January 2005 and December 2012. Two patients with inadequate information and all eleven male patients were excluded from the analysis. The remaining 674 women with breast cancer form the basis of the study.

\section{Clinical presentation and tumor characteristics}

Most patients $(622,92.3 \%)$ had unilateral primary breast cancer, mainly as a single primary (534 cases, $79.2 \%$ ) or in association with other primary cancers, either concurrently or sequentially $(88,13.1 \%)$. Twenty women $(2.9 \%)$ had simultaneous bilateral breast cancer; and 32 (4.7\%) had metachronous bilateral breast cancer, with the second contralateral breast cancer diagnosed after a mean duration of 90 months. Median age at initial diagnosis of unilateral, simultaneous bilateral, or metachronous first primary cancer was 58.2, 61.6, and 57.4 years, respectively. Among 442 patients with unilateral primary cancer, 232 (52.5\%) had the tumor at the upper outer quadrant, 74 (16.7\%) at the upper inner quadrant, $31(7.0 \%)$ at a central location, $30(6.8 \%)$ at the lower inner quadrant, $27(6.1 \%)$ at the lower outer quadrant, and $48(10.9 \%)$ in between quadrants. This distribution was not significantly different in relation to tumor laterality or family history.

Twenty-one patients were tested for the breast cancer susceptibility (BRCA-I/II) gene mutation. One was found to have $B R C A-I$ and four were found to have $B R C A$ - $I I$ gene mutations, while the rest were negative for both tumor genes. Most patients $(640,95.0 \%)$ had invasive breast cancer while $34(5.0 \%)$ had ductal or lobular carcinoma in situ.
The majority of invasive carcinomas were duct cell (490, $72.7 \%)$, followed by lobular $(45,6.7 \%)$, mixed ductal and lobular $(43,6.4 \%)$, medullary $(10,1.5 \%)$, as well as other subtypes, and undetermined (52, 7.7\%). Most tumors were poorly differentiated $(236 / 550,42.9 \%)$, followed by moderately differentiated $(213 / 550,38.7 \%)$ and well differentiated $(101 / 550,18.4 \%)$. Angiolymphatic invasion was absent $(135 / 211,64.0 \%)$ or present $(76 / 211,36.0 \%)$. Tumors were estrogen receptor-positive or progesterone receptor-positive $(477 / 618,77.2 \%)$ or both negative $(141$, $22.8 \%$ ). HER $2 /$ neu status was negative $(428 / 521,82.1 \%)$ or positive $(93 / 521,17.9 \%)$. Eighty-nine patients of $521(17.1 \%)$ were both estrogen receptor-negative and progesterone receptor-negative as well as HER2/neu negative (triple negative). Most patients initially presented with no lymph node metastases (N0, 386/644 patients, 59.9\%), minimal involvement (N1, 154/644 patients, 23.9\%), intermediate lymphadenopathy (N2, 73/644 cases, $11.3 \%$ ), or extensive lymph node metastases (N3, 31/644 patients, 4.8\%).

Patients were followed up for a mean duration of 27.04 months. At the end of the study, most patients (493/674, 73.1\%) were still alive, and a smaller number (181 patients, 26.9\%) had died, from progressive malignancy (142 cases, 78.4\%), treatment-related causes (three patients, $1.7 \%$ ), medical or age-related causes (22 patients, $12.2 \%$ ), other reasons (seven cases, 3.9\%), or undetermined (seven cases, $3.9 \%$ ). Overall, there were no statistically significant differences between various groups in relation to breast cancer laterality, whether cancer was unilateral or bilateral, and whether or not there was a family history of breast cancer.

\section{Laterality of breast cancer}

Demographic data on patients with breast cancer according to disease laterality are shown in Table 1 . A relative excess incidence of left over right breast cancer was noted in all age groups, except those under 30 years, over 90 years, and 50-59 years (Figure 1). In all 654 patients initially presenting with unilateral breast cancer, left side predominance persisted, even after exclusion of 45 patients with lobular adenocarcinoma (remaining 612 patients, $52.5 \%$ on left side), exclusion of 34 cases of ductal or lobular carcinoma in situ (remaining 620 patients, $52.9 \%$ on left side), and inclusion of male patients with breast cancer (eleven patients, $54.5 \%$ on left side), and patients with triple-negative breast cancer ( 89 cases, $58.4 \%$ on the left side). Left side predominance was also noted in patients of Caucasian and African American ancestry. However, the differences were not statistically significant (Table 1). There were no significant differences between left-sided versus right-sided 
Table I Patient demographic data according to breast cancer laterality

\begin{tabular}{|c|c|c|c|c|c|}
\hline & $\begin{array}{l}\text { Left breast } \\
\text { n (\%) }\end{array}$ & $\begin{array}{l}\text { Right breast } \\
\text { n (\%) }\end{array}$ & $P$-value* & $\begin{array}{l}\text { Bilateral breast } \\
\text { n (\%) }\end{array}$ & $P$-value** \\
\hline Patients & $343(50.9)$ & $311(46.1)$ & & $20(3.0)$ & \\
\hline \multicolumn{6}{|l|}{ Age at diagnosis, years } \\
\hline$\leq 64$ & $219(63.9)$ & $218(70.1)$ & 0.09 & $10(50.0)$ & 0.07 \\
\hline$\geq 65$ & $124(36.1)$ & $93(29.9)$ & & $10(50.0)$ & \\
\hline$\leq 44$ & $54(15.7)$ & $60(19.3)$ & 0.2 & I (5.0) & 0.1 \\
\hline$\geq 45$ & $289(84.3)$ & $25 \mathrm{I}(80.7)$ & & $19(95)$ & \\
\hline \multicolumn{6}{|l|}{ Ethnicity } \\
\hline Caucasian & $217(66.6)$ & $196(66.2)$ & 0.6 & $13(72.2)$ & 0.8 \\
\hline African American & $99(30.4)$ & 85 (28.7) & & $5(27.8)$ & \\
\hline Native American Indian & $5(1.5)$ & $7(2.4)$ & & 0 & \\
\hline Others & $5(1.5)$ & $8(2.7)$ & & 0 & \\
\hline \multicolumn{6}{|l|}{ Body mass index } \\
\hline Underweight & $7(2.5)$ & $9(3.4)$ & 0.8 & 0 & 0.9 \\
\hline Normal weight & $65(22.9)$ & $62(23.0)$ & & $4(25.0)$ & \\
\hline Overweight & $212(74.6)$ & $198(73.6)$ & & $12(75.0)$ & \\
\hline \multicolumn{6}{|l|}{ Atherosclerosis } \\
\hline None apparent & $255(74.3)$ & $227(73.0)$ & 0.6 & $12(60.0)$ & 0.3 \\
\hline Present & $88(25.7)$ & $84(27.0)$ & & $8(40.0)$ & \\
\hline \multicolumn{6}{|l|}{ Smoking } \\
\hline Nonsmoker & $180(55.0)$ & $169(56.5)$ & 0.7 & $10(50.0)$ & 0.8 \\
\hline Smoker & I $47(45.0)$ & $130(43.5)$ & & $10(50.0)$ & \\
\hline \multicolumn{6}{|l|}{ Thrombosis } \\
\hline No thrombosis & $303(88.3)$ & $275(88.4)$ & 0.9 & $18(90.0)$ & 0.9 \\
\hline Thrombosis & $40(11.7)$ & $36(11.6)$ & & $2(10.0)$ & \\
\hline \multicolumn{6}{|l|}{ Handedness } \\
\hline Right & $91(91.0)$ & $80(90.9)$ & 0.9 & $7(87.5)$ & 0.9 \\
\hline Non-right & $9(9.0)$ & $8(9.1)$ & & I (I2.5) & \\
\hline \multicolumn{6}{|l|}{ Number of primaries } \\
\hline Single primary & $276(80.5)$ & $258(83.0)$ & 0.5 & $18(90.0)$ & 0.6 \\
\hline Two primaries & $60(17.5)$ & $45(14.5)$ & & $2(10.0)$ & \\
\hline Three/more primaries & $7(2.0)$ & $8(2.5)$ & & 0 & \\
\hline \multicolumn{6}{|l|}{ Unilateral and bilateral cancers } \\
\hline Unilateral & $324(94.5)$ & $298(95.8)$ & 0.7 & 0 & \\
\hline Bilateral simultaneous & 0 & 0 & & $20(100)$ & \\
\hline Bilateral metachronous & $19(5.5)$ & $13(4.2)$ & & 0 & \\
\hline \multicolumn{6}{|c|}{ Family history of breast cancer } \\
\hline First-degree relatives & $100(31.7)$ & $75(27.3)$ & 0.4 & $3(16.7)$ & 0.1 \\
\hline Second-degree relatives & $50(15.9)$ & $52(18.9)$ & & $7(38.9)$ & \\
\hline No family history & $165(52.4)$ & $148(53.8)$ & & $8(44.4)$ & \\
\hline \multicolumn{6}{|l|}{ Tumor multicentricity } \\
\hline Unifocal neoplasm & $210(77.2)$ & $202(83.8)$ & 0.0601 & $6(31.6)$ & 0.0000 \\
\hline Multifocal neoplasm & $62(22.8)$ & $39(16.2)$ & & $13(68.4)$ & \\
\hline \multicolumn{6}{|l|}{ Initial stage } \\
\hline $0 / 1$ & $128(37.3)$ & $123(39.6)$ & 0.2 & I (5.0) & 0.0344 \\
\hline II & $|4|(4||)$. & $105(33.8)$ & & $12(60.0)$ & \\
\hline III & $55(16.0)$ & $61(19.6)$ & & $5(25.0)$ & \\
\hline IV & $19(5.5)$ & $22(7.0)$ & & $2(10.0)$ & \\
\hline \multicolumn{6}{|l|}{ Overall survival, years } \\
\hline Mean \pm SD & $6.77 \pm 6.56$ & $7.50 \pm 7.17$ & 0.1 & $4.69 \pm 4.86$ & 0.0850 \\
\hline Median & 4.78 & 5.18 & & 3.37 & \\
\hline At 5 & 55 & 59 & 0.2 & 30 & 0.0695 \\
\hline At 10 & 31 & 32 & & 18 & \\
\hline At 15 & 20 & 20 & & 18 & \\
\hline
\end{tabular}

Notes: *Statistically significant difference between left and right breast cancers; ${ }^{* *}$ statistically significant difference between the three groups.

Abbreviation: SD, standard deviation. 


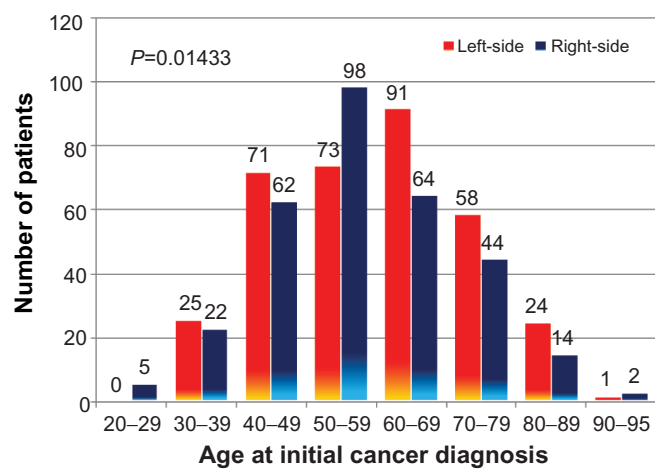

Figure I Laterality of breast cancer according to age at initial diagnosis.

breast cancers, especially in regards to clinical presentation or tumor characteristics (Table 1).

When bilateral breast cancer was compared with unilateral left-sided or right-sided neoplasms, patients with synchronous bilateral breast cancer usually had multicentric malignancies of a lower grade, and usually presented in earlier stages of the disease (Table 1). For the 32 patients with metachronous breast cancer, the disease first occurred more often in the left breast (19 patients, 59.4\%), compared with the right breast (13 cases, $40.6 \%$ ). Subsequent breast primary was in the contralateral breast. In the 20 patients with simultaneous bilateral breast cancers, eleven (55\%) had more advanced disease on the right side, eight $(40 \%)$ on the left side, and one was relatively equal in sizes at both sides.

Demographic data on unilateral and bilateral breast cancers are shown in Table 2. Patients with metachronous breast cancer were relatively younger in age at initial presentation, tended to have multiple neoplasms that were multicentric in nature, initially detected at an earlier stage of disease, and a strong family history of breast cancer compared with those having unilateral or simultaneous bilateral breast cancers (Table 2).

\section{Family history and breast cancer laterality}

The clinical presentation of patients with and without a family history of breast cancer is shown in Table 3. Patients with a family history of breast cancer were usually younger in age, with no apparent clinical evidence of atherosclerosis, and had a higher tendency to develop bilateral breast cancer especially of the metachronous type (Table 2). Among the eleven patients with male breast cancer, one had a family history of breast cancer, namely an uncle.

When breast cancer laterality was compared between patients and their relatives, there was concordance between both groups in $45.5 \%$ of first-degree relatives and $17.7 \%$ among second-degree relatives, compared with a discordance rate of $13.6 \%$ and $29.4 \%$, respectively ( $P=0.01163$, Table 4$)$. When patients with bilateral breast cancer were excluded, the statistical differences reached a higher level $(P=0.00711)$. Such concordance in relation to breast cancer laterality was strongest among patients and their sisters (53.1\%) and between patients and their mothers $(40.7 \%)$. However, due to their small numbers, the differences were not statistically significant (Table 4).

When the age at initial cancer diagnosis was compared between patients and their relatives, there was concordance between the two groups in $27.6 \%$ of cases for differences in age of 5 years or less (Table 5). Among first-degree relatives, $14(8.4 \%)$ developed breast cancer at the same age as the patient, and 34 (20.4\%) within 3 years either side of the patient's age. This concordance was very noticeable among patients' sisters and mothers. However, due to their small numbers, the differences were not statistically significant (Table 5).

\section{Impact on survival}

There was no statistically significant difference in survival between patients with left or right breast cancers (Figure 2), those with or without a family history of cancer (Figure 3), or in relation to handedness $(P=0.9198)$. Patients with simultaneous bilateral breast cancer fared worse compared with those with left-sided or right-sided breast cancers (Table 1). They also fared worse compared with those having metachronous bilateral breast cancers, but had similar survival to those with unilateral breast cancer (Table 2 and Figure 4). The best survival was noted for patients with metachronous bilateral breast cancer, ie, $90 \%$ at 10 years compared with $28 \%$ for unilateral breast cancer and $18 \%$ for simultaneous bilateral breast cancer (Table 2 and Figure 4). This survival advantage persists even if one limits the study to patients initially diagnosed between 2005 and 2012 ( $P=0.03503)$.

\section{Discussion}

\section{Human development and asymmetry}

Humans, like other vertebrates, show an apparent bilateral symmetry in paired morphological traits, such as ear size, digit length, and breast volume. However, perfect symmetry is disturbed by several intrinsic and extrinsic factors, particularly during fetal development. Paired organs may differ in their tissue volume, structure, position, arterial and venous supply, and lymphatic drainage, as well as their physiological relationship to other organs. ${ }^{6}$ Bilateral asymmetry of the brain is well known, and connected to behavioral factors such as handedness and complex sociological phenomena. ${ }^{7}$ 
Table 2 Patient demographic data for single versus bilateral breast cancers

\begin{tabular}{|c|c|c|c|c|}
\hline & $\begin{array}{l}\text { Unilateral } \\
\text { n (\%) }\end{array}$ & $\begin{array}{l}\text { Bilateral simultaneous } \\
\text { n (\%) }\end{array}$ & $\begin{array}{l}\text { Bilateral metachronous } \\
\text { n (\%) }\end{array}$ & $P$-value* \\
\hline Patient age & $622(92.3)$ & $20(3.0)$ & $32(4.7)$ & \\
\hline \multicolumn{5}{|l|}{ Age at diagnosis, years } \\
\hline$\leq 64$ & $413(66.4)$ & $10(50.0)$ & $24(75.0)$ & 0.17 \\
\hline$\geq 65$ & $209(33.6)$ & $10(50.0)$ & $8(25.0)$ & \\
\hline Mean \pm SD & $58.8 \pm 13.5$ & $64.3 \pm 15.5$ & $54.7 \pm 13.9$ & \\
\hline \multicolumn{5}{|l|}{ Ethnicity } \\
\hline Caucasian & $391(66.2)$ & $13(72.2)$ & $22(71.0)$ & 0.92 \\
\hline African American & $177(29.9)$ & $5(27.8)$ & $7(22.6)$ & \\
\hline Native American Indians & II (I.9) & 0 & I (3.2) & \\
\hline Others & $12(2.0)$ & 0 & I (3.2) & \\
\hline \multicolumn{5}{|l|}{ Body mass index } \\
\hline Underweight & $15(2.9)$ & 0 & I (3.3) & 0.94 \\
\hline Normal weight & $119(22.8)$ & $4(25.0)$ & $8(26.7)$ & \\
\hline Overweight & $389(74.4)$ & $12(75.0)$ & $21(70.0)$ & \\
\hline \multicolumn{5}{|l|}{ Atherosclerosis } \\
\hline None apparent & $456(73.3)$ & $12(60.0)$ & $26(81.3)$ & 0.24 \\
\hline Present & $166(26.7)$ & $8(40.0)$ & $6(18.8)$ & \\
\hline \multicolumn{5}{|l|}{ Smoking } \\
\hline Nonsmoker & $331(55.5)$ & $10(50.0)$ & $18(60.0)$ & 0.78 \\
\hline Smoker & $265(44.5)$ & $10(50.0)$ & $12(40.0)$ & \\
\hline \multicolumn{5}{|l|}{ Thrombosis } \\
\hline No thrombosis & $554(89.1)$ & $18(90.0)$ & $24(75.0)$ & 0.05143 \\
\hline Thrombosis & $68(10.9)$ & $2(10.0)$ & $8(25.0)$ & \\
\hline \multicolumn{5}{|l|}{ Handedness } \\
\hline Right & $169(91.4)$ & $7(87.5)$ & $2(66.7)$ & 0.32 \\
\hline Non-right & $16(8.7)$ & I (I2.5) & I (33.3) & \\
\hline \multicolumn{5}{|l|}{ Number of primaries } \\
\hline Single primary & $534(85.9)$ & $18(90.0)$ & 0 & 0.0000 \\
\hline Two primaries & $80(12.9)$ & $2(10.0)$ & $25(78.1)$ & \\
\hline Three/more primaries & $8(1.3)$ & 0 & $7(21.9)$ & \\
\hline \multicolumn{5}{|l|}{ Breast cancer laterality } \\
\hline Left & $324(52.1)$ & & $19(59.4)$ & 0.72 \\
\hline Right & $298(47.9)$ & & $13(40.6)$ & \\
\hline \multicolumn{5}{|c|}{ Family history of breast cancer } \\
\hline First-degree relatives & $157(27.9)$ & $3(16.7)$ & $18(66.7)$ & 0.00006 \\
\hline Second-degree relatives & $100(17.8)$ & $7(38.9)$ & $2(7.4)$ & \\
\hline No family history & $306(54.4)$ & $8(44.4)$ & $7(25.9)$ & \\
\hline \multicolumn{5}{|l|}{ Tumor multicentricity } \\
\hline Unifocal neoplasm & $385(79.6)$ & $6(31.6)$ & $27(93.1)$ & 0.0000 \\
\hline Multifocal neoplasm & $99(20.5)$ & $13(68.4)$ & $2(6.9)$ & \\
\hline \multicolumn{5}{|l|}{ Initial stage } \\
\hline $0 / 1$ & $243(39.1)$ & I (5.0) & $8(25.0)$ & 0.01487 \\
\hline II & $228(36.7)$ & $12(60.0)$ & $18(56.3)$ & \\
\hline III & $113(18.2)$ & $5(25.0)$ & $3(9.4)$ & \\
\hline IV & $38(6.1)$ & $2(10.0)$ & $3(9.4)$ & \\
\hline \multicolumn{5}{|l|}{ Overall survival, years } \\
\hline Mean \pm SD & $6.66 \pm 6.48$ & $4.69 \pm 4.86$ & $16.05 \pm 8.00$ & 0.0000 \\
\hline Median & 4.78 & 3.37 & 14.83 & \\
\hline At 5 & 55 & 30 & 97 & 0.0000 \\
\hline At 10 & 28 & 18 & 90 & \\
\hline At 15 & 17 & 0 & 66 & \\
\hline
\end{tabular}

Note: *Statistically significant difference between bilateral simultaneous and bilateral metachronous breast cancers.

Abbreviation: SD, standard deviation.

Autopsy data showed a different left-right organ size ratio of 0.87 for the lungs and 0.87 for the testes, reflecting larger sizes on the right. ${ }^{6}$ Laterality, which is tightly controlled during fetal development, may also affect the spatial occurrence of disease. Determination of left-sided and right-sided organ sites takes place before and during gastrulation. Its failure results in heterotaxia, with congenital laterality disorders characterized by left-right displacement of organs. ${ }^{7}$ Several secreted and membrane-bound growth factors such as Nodal, Lefty, fibroblast growth factor (FGF), heparin-binding 
Table 3 Clinical presentation of patients with and without family history of breast cancer

\begin{tabular}{|c|c|c|c|c|}
\hline & $\begin{array}{l}\text { Family history } \\
\text { n (\%) }\end{array}$ & $\begin{array}{l}\text { No family history } \\
\text { n (\%) }\end{array}$ & $P$-value & $\begin{array}{l}\text { All patients* } \\
\text { n (\%) }\end{array}$ \\
\hline Patients & $287(42.6)$ & $321(47.6)$ & & 674 \\
\hline \multicolumn{5}{|l|}{ Age at diagnosis, years } \\
\hline$\leq 64$ & $206(71.8)$ & $204(63.6)$ & 0.03072 & $447(66.3)$ \\
\hline$\geq 65$ & $81(28.2)$ & $117(36.5)$ & & $227(33.7)$ \\
\hline \multicolumn{5}{|l|}{ Ethnicity } \\
\hline Caucasian & $180(65.9)$ & $209(66.8)$ & 0.17 & $426(66.6)$ \\
\hline African American & $82(30.0)$ & $90(28.8)$ & & $189(29.5)$ \\
\hline Native American Indian & $8(2.9)$ & $4(1.3)$ & & $12(1.9)$ \\
\hline Others & $3(1.1)$ & $10(3.2)$ & & $13(2.0)$ \\
\hline \multicolumn{5}{|l|}{ Body mass index } \\
\hline Underweight & $5(2.0)$ & $9(3.2)$ & 0.11 & $16(2.8)$ \\
\hline Normal weight & $47(19.0)$ & $72(25.6)$ & & $|3|(23.0)$ \\
\hline Overweight & $196(79.0)$ & $200(7 \mid .2)$ & & $422(74.2)$ \\
\hline \multicolumn{5}{|l|}{ Atherosclerosis } \\
\hline None apparent & $228(79.4)$ & $226(70.4)$ & 0.01053 & $494(73.3)$ \\
\hline Present & $59(20.6)$ & $95(29.6)$ & & $180(26.7)$ \\
\hline \multicolumn{5}{|l|}{ Smoking } \\
\hline Nonsmoker & $157(55.5)$ & $179(57.0)$ & 0.70 & $359(55.6)$ \\
\hline Smoker & $126(44.5)$ & $135(43.0)$ & & $287(44.4)$ \\
\hline \multicolumn{5}{|l|}{ Thrombosis } \\
\hline No thrombosis & $260(90.6)$ & $278(86.6)$ & 0.12 & $596(88.4)$ \\
\hline Thrombosis & $27(9.4)$ & $43(13.4)$ & & $78(11.6)$ \\
\hline \multicolumn{5}{|l|}{ Handedness } \\
\hline Right & $85(91.4)$ & $91(90.1)$ & 0.75 & $178(90.8)$ \\
\hline Non-right & $8(8.6)$ & $10(9.9)$ & & $18(9.2)$ \\
\hline \multicolumn{5}{|l|}{ Number of primaries } \\
\hline Single primary & $237(82.6)$ & $264(82.2)$ & 0.70 & $552(81.9)$ \\
\hline Two primaries & $42(14.6)$ & $51(15.9)$ & & $107(15.9)$ \\
\hline Three/more primaries & $8(2.8)$ & $6(1.9)$ & & $15(2.2)$ \\
\hline \multicolumn{5}{|c|}{ Unilateral and bilateral cancers } \\
\hline Unilateral & $257(89.5)$ & $306(95.3)$ & 0.01184 & $622(92.3)$ \\
\hline Bilateral simultaneous & $10(3.5)$ & $8(2.5)$ & & $20(3.0)$ \\
\hline Bilateral metachronous & $20(7.0)$ & $7(2.2)$ & & $32(4.7)$ \\
\hline \multicolumn{5}{|l|}{ Breast cancer laterality } \\
\hline Left & $150(52.3)$ & $165(5 \mathrm{I} .4)$ & 0.72 & $343(50.9)$ \\
\hline Right & $127(44.3)$ & $148(46.1)$ & & $311(46.1)$ \\
\hline Bilateral & $10(3.4)$ & $8(2.5)$ & & $20(3.0)$ \\
\hline \multicolumn{5}{|l|}{ Tumor multicentricity } \\
\hline Unifocal neoplasm & $188(80.0)$ & $204(78.8)$ & 0.73 & $418(78.6)$ \\
\hline Multifocal neoplasm & $47(20.0)$ & $55(21.2)$ & & $1 \mid 4(2 \mid .4)$ \\
\hline \multicolumn{5}{|l|}{ Initial stage } \\
\hline $0 / 1$ & $107(37.3)$ & $116(36.1)$ & 0.92 & 252 \\
\hline II & $112(39.0)$ & $129(40.2)$ & & 258 \\
\hline III & $48(16.7)$ & $57(17.8)$ & & 121 \\
\hline IV & $20(7.0)$ & $19(5.9)$ & & 43 \\
\hline \multicolumn{5}{|l|}{ Overall survival, years } \\
\hline Mean \pm SD & $6.79 \pm 6.17$ & $7.00 \pm 6.80$ & 0.68 & $7.05 \pm 6.82$ \\
\hline Median & 4.99 & 4.77 & & 4.87 \\
\hline At 5 & 56 & 56 & 0.71 & \\
\hline At 10 & 28 & 31 & & \\
\hline At 15 & 14 & 23 & & \\
\hline
\end{tabular}

Note: *All patients, including 66 patients with inadequate information regarding family history.

Abbreviation: SD, standard deviation.

epidermoid growth factor (HB-EGF), and hepatocyte growth factor (HGF) as well as transcription factors such as pituitary homeobox 2 (Pitx2) and Forkhead box A2 (Foxa2) may act as molecular controllers of left-right asymmetry. They may also contribute to development of cancer. ${ }^{7}$

\section{Laterality in cancer}

Earlier studies have reported right-sided lateralization for different organ cancers except for breast cancer and malignant melanoma. ${ }^{7}$ In a large study of a UK cohort involving about one quarter of a million cancer patients, the incidence of can- 
Table 4 Laterality of breast cancer among relatives compared with patient's initial primary cancer site

\begin{tabular}{|c|c|c|c|c|c|c|c|}
\hline & $\begin{array}{l}\text { Same side } \\
\text { (as patient) } \\
\text { n (\%) }\end{array}$ & $\begin{array}{l}\text { Opposite side } \\
\text { (to patient) } \\
\text { n (\%) }\end{array}$ & $P$-value* & $\begin{array}{l}\text { Either side (for } \\
\text { bilateral cancers) } \\
\mathbf{n}(\%)\end{array}$ & $P$-value** & $\begin{array}{l}\text { Inadequate } \\
\text { information, } \\
n\end{array}$ & $\begin{array}{l}\text { Total, all } \\
\text { relatives, } \\
\mathbf{n}\end{array}$ \\
\hline Patients & $36(36.0)$ & $19(19.0)$ & & $45(45.0)$ & & 267 & 367 \\
\hline \multicolumn{8}{|l|}{ Family members } \\
\hline Daughter & $2(28.6)$ & I (I4.3) & 0.08 & $4(57.1)$ & 0.0689 & 5 & 12 \\
\hline Sister & $17(53.1)$ & $4(12.5)$ & & II (34.4) & & 70 & 102 \\
\hline Mother & II (40.7) & $4(14.8)$ & & $12(44.4)$ & & 53 & 80 \\
\hline Father & 0 & 0 & & 0 & & 2 & 2 \\
\hline Aunt & I (4.6) & $6(27.3)$ & & $15(68.2)$ & & 89 & 111 \\
\hline Uncle & 0 & 0 & & 0 & & 2 & 2 \\
\hline Grandmother & $5(4 I .7)$ & $4(33.3)$ & & $3(25.0)$ & & 46 & 58 \\
\hline \multicolumn{8}{|l|}{ Family relatives } \\
\hline First-degree & $30(45.5)$ & $9(13.6)$ & $0.007 \mid I$ & $27(40.9)$ & 0.01163 & 132 & 198 \\
\hline Second-degree & $6(17.7)$ & $10(29.4)$ & & $18(52.9)$ & & 135 & 169 \\
\hline \multicolumn{8}{|l|}{ First-degree relatives } \\
\hline One member & $23(52.3)$ & $8(18.2)$ & 0.39 & I $3(29.6)$ & 0.02332 & 97 & $|4|$ \\
\hline Multiple members & $7(31.8)$ & I (4.6) & & $14(63.6)$ & & 35 & 57 \\
\hline
\end{tabular}

Notes: *Statistically significant differences between the two groups; **statistically significant differences between the three groups (using Fisher's exact test); ${ }^{*}$ either side of breast cancer laterality for close relatives of patients with bilateral breast cancer. All relatives with bilateral breast cancers were excluded from the analysis.

cer differed significantly by laterality at all sites studied. The incidence ratio (left to right) was 0.88 for lung cancer, 0.87 for testicular cancer, 0.99 for ovarian germ cell tumors, 0.96 for male kidney cancer, and 0.94 for female kidney cancers. The same ratio was 1.07 for breast cancer. ${ }^{6}$

A relative excess incidence of left over right breast cancer has been well documented in the literature, with the left to right side ratio ranging from 1.05 to $1.26 .^{2,6,8} \mathrm{~A}$ detailed analysis of over 250,000 breast cancer cases from the Surveillance, Epidemiology, and End Results program in the USA between 1973 and 1992 confirmed the results from other studies. There was an overall 5\% excess of left-sided breast cancer in women over 45 years. The excess occurred for all races, stage of disease at presentation, and for invasive cancer; furthermore, this excess increases with age. There was no excess of left-sided laterality in men. ${ }^{8}$ In another study from Sweden of 84,619 patients with breast cancer seen between 1970 and 1989, the left to right ratio was 1.07 for women aged 45 years and above, with left-sided predominance reported for both invasive and in situ cancers and in men and women, which was much higher in the older age groups. ${ }^{2}$ Other studies based on selected populations have failed to find a significant excess of left-sided breast cancer., ${ }^{9,10}$ Controversy exists over whether the excess of left-sided breast cancer, as suggested by some authors, is confined to women older than 45 years of age ${ }^{2,8}$ or for all ages. ${ }^{9}$ However, because the excess risk of

Table 5 Differences in age between patients and their relatives at time of initial breast cancer diagnosis

\begin{tabular}{|c|c|c|c|c|c|c|c|}
\hline \multirow{2}{*}{$\begin{array}{l}\text { Family } \\
\text { members }\end{array}$} & \multicolumn{5}{|c|}{ Relatives with breast cancer } & \multirow{2}{*}{$\begin{array}{l}\text { Relatives } \\
\text { with ovarian } \\
\text { cancer }\end{array}$} & \multirow{2}{*}{$\begin{array}{l}\text { Total all } \\
\text { relatives* }\end{array}$} \\
\hline & $\begin{array}{l}\text { I-5 years } \\
\text { difference } \\
n(\%)\end{array}$ & $\begin{array}{l}\text { 6-10 years } \\
\text { difference } \\
n(\%)\end{array}$ & $\begin{array}{l}\text { > I I years } \\
\text { difference } \\
\text { n (\%) }\end{array}$ & $P$-value* & $\begin{array}{l}\text { Inadequate } \\
\text { information }\end{array}$ & & \\
\hline Patients & $69(27.6)$ & $44(17.6)$ & $137(54.8)$ & & 117 & 37 & 404 \\
\hline \multicolumn{8}{|l|}{ Family members } \\
\hline Daughter & $2(18.2)$ & $2(18.2)$ & $7(63.6)$ & 0.48 & 1 & 0 & 12 \\
\hline Sister & $29(36.7)$ & $14(17.7)$ & $36(45.6)$ & & 23 & 8 & 110 \\
\hline Mother & $17(22.7)$ & $18(24.0)$ & $40(53.3)$ & & 5 & 7 & 87 \\
\hline Father & 0 & 0 & $\mathrm{I}(100)$ & & 1 & & 2 \\
\hline Aunt & $14(24.1)$ & $7(12.1)$ & $37(63.8)$ & & 53 & 12 & 123 \\
\hline Uncle & 0 & 0 & I $(100)$ & & I & & 2 \\
\hline Grandmother & $7(28.0)$ & $3(12.0)$ & $15(60.0)$ & & 33 & 10 & 68 \\
\hline \multicolumn{8}{|l|}{ Family relationship } \\
\hline First-degree & $48(28.9)$ & $34(20.5)$ & $84(50.6)$ & 0.12 & 30 & 15 & 211 \\
\hline Second-degree & $21(25.0)$ & $10(11.9)$ & $53(63.1)$ & & 87 & 22 & 193 \\
\hline
\end{tabular}

Note: *Statistically significant differences between the three groups (using Fisher's exact test). 


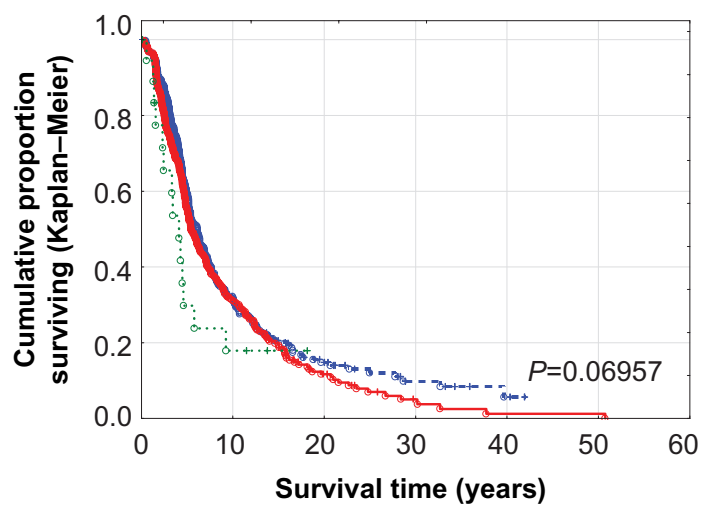

- Left breast median: 4.78 years

-. Right breast median: 5.18 years

Bilateral median: 3.37 years

Figure 2 Survival of breast cancer patients according to disease laterality.

cancer in the left breast is small, a large number of cases are necessary to meaningfully evaluate laterality in population subgroups. ${ }^{9}$ In the present study, breast cancer was noted to be predominantly on the left side, with a left to right ratio of 1.1, and such laterality was noted at all ages except for patients aged 50-59 years, and for those younger than 30 years or older than 90 years. However, the number of patients at the extremes of age was relatively low. Hence, the outcome was not statistically significant.

\section{Unilateral and bilateral breast cancers}

The breast is a paired organ, so hormonal, environmental, and genetic factors are likely to affect the breast over time. Therefore, bilateral breast cancer is not uncommon. This was much more noticeable in patients with hereditary disorders. Women who carry a germline mutation in either the BRCA-I

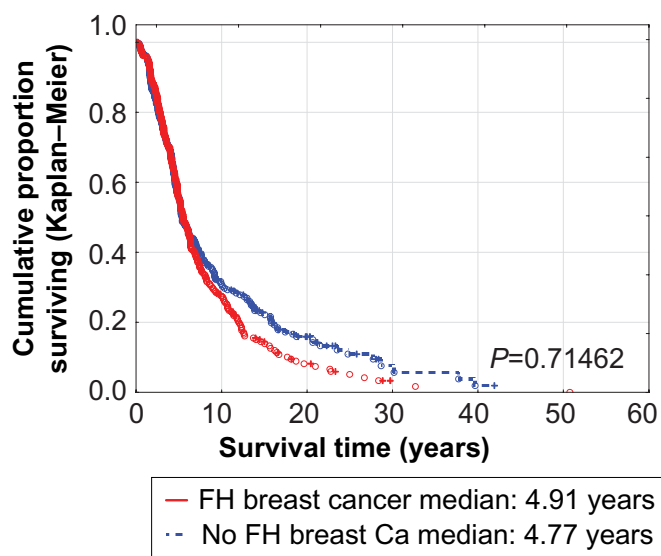

Figure 3 Survival of breast cancer patients with and without a family history of similar malignancy.

Abbreviations: $\mathrm{Ca}$, Cancer; FH, Family history of breast cancer.

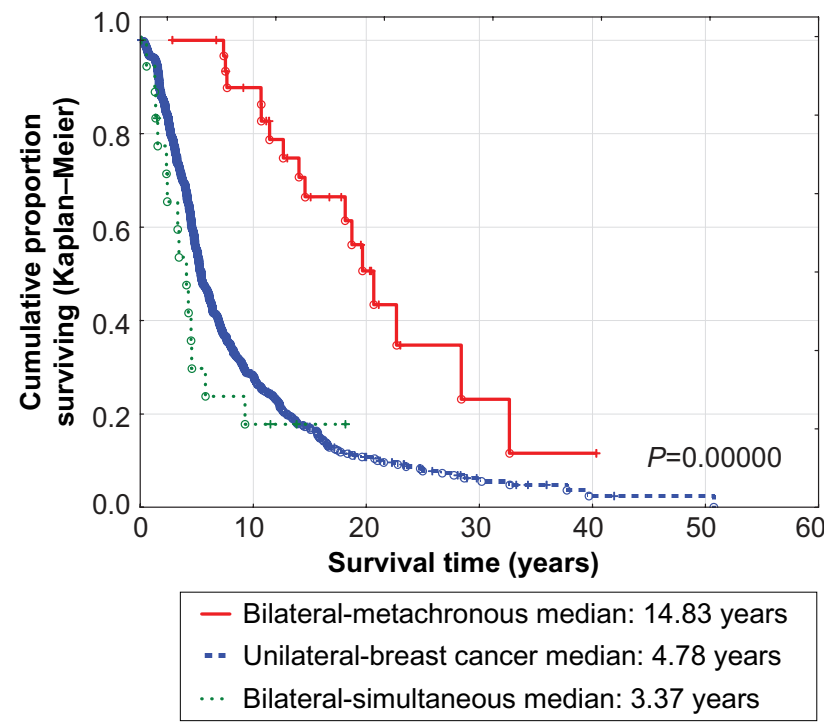

Figure 4 Survival of patients with unilateral, simultaneous bilateral, and metachronous bilateral breast cancers, showing statistically significant differences between the three groups $(P=0.00000)$ and between unilateral versus simultaneous bilateral breast cancers $(P=0.08722)$.

or BRCA-II genes face a high risk of developing contralateral breast cancer. The actual risk varies from $29.5 \%$ to $40 \%$ at 10 years. ${ }^{11}$

In general, the prevalence of simultaneous (synchronous) bilateral breast cancer was $0.8 \%-2.9 \% .^{12,13}$ Approximately $5 \%-10 \%$ of women treated for breast cancer subsequently developed cancer in the contralateral breast, with an annual risk of $0.6 \%$ and a cumulative rate that increased from 5.6\% at 10 years to $9.9 \%$ at 15 years of follow-up. ${ }^{12,14}$ Usually such patients presented at a younger age, with a small sized tumor, low-grade histology, lymph node-negative malignancy, at an earlier stage of disease, were more likely to have lobular histology but no angiolymphatic invasion, commonly had a strong family history in first-degree relatives, and lived long enough to experience bilateral disease. ${ }^{12}$ Similar results were observed in the present study. Patients with metachronous breast cancer were relatively younger in age, tended to have multiple neoplasms that were multicentric in nature, were at an earlier stage of disease, had a strong family history of breast cancer in comparison with those having unilateral or synchronous bilateral breast cancer, and had the best survival. These characteristics suggest a possible genetic predisposition.

\section{Management of breast cancer and laterality}

Radiation therapy is a critical component of conservative therapy for breast cancer. Despite the reduction in local 
recurrence in the breast, women with left-sided breast cancer treated with radiation therapy were at greater risk of late development of cardiovascular complications, including myocardial infarction and stroke, secondary to radiation exposure in the heart and carotid region. This has led to a higher mortality rate, especially in patients with left-sided breast cancer and pre-existing ischemic heart disease (27\%) compared with the right side $(9 \%) .{ }^{15,16}$ With the introduction of modern radiation therapy techniques, the estimated risk has gradually dropped and become nearly negligible. ${ }^{15}$ Nevertheless, in a study of 961 patients with early stage I/II disease treated with radiation, there was a higher incidence of cardiac stress abnormalities (59\%) with partial occlusion of the left anterior descending coronary artery (70\%) on cardiac catheterization in patients with left-sided malignancy, compared with $8 \%$ and $62 \%$, respectively, for right breast cancer. $^{17}$

\section{Breast cancer laterality and survival}

The prognosis of breast cancer has improved, with "curative" 10 -year survival rates of about $70 \%$ in most Western populations. ${ }^{18}$ Patients with simultaneous bilateral breast malignancies have the worst survival, compared with those having unilateral disease. This generally poor prognosis gradually diminishes as the interval between the two breast primaries increases. Survival is the best for metachronous bilateral cancer, especially when the interval between first and second malignancy exceeds 5 years. ${ }^{19}$ In the present analysis, the 5-year survival for all patients was 56\%. The worst survival was for patients with simultaneous bilateral breast cancer (5-year survival of 30\% versus 55\% for unilateral breast cancer and $97 \%$ for metachronous bilateral breast cancer). There was no impact of family history or cancer laterality on subsequent breast cancer survival.

\section{Possible explanation for breast cancer laterality}

Several investigators have raised the possibility of detection bias as an explanation for the predominance of left-sided breast cancer. The vast majority of women are right-handed, so it might be easier to detect a palpable lump in the left breast compared with the right. ${ }^{1}$ However, a large, population-based, case-control study found that left-handed women were at greater risk than right-handed women of developing breast cancer in either breast, and failed to find any association between handedness and breast cancer laterality. ${ }^{9,10}$

Two case studies ${ }^{1,2}$ reported that nulliparous women younger than 45 years of age with breast cancer did not show a left-sided predominance, and a large population-based study reported that left-sided predominance increased with age at diagnosis and was of borderline significance in women younger than 55 years of age. ${ }^{8,9}$ In the present analysis, age and ethnicity were unrelated to breast cancer laterality.

Several reports have shown left breast size to be somewhat larger than the right, and therefore to have more tissue at risk of cancer. ${ }^{1,2,9}$ Fluctuations in breast size have been documented under normal physiological conditions in adult women, particularly during menses, pregnancy, and lactation, at which time asymmetric breast enlargement is frequently encountered. ${ }^{1}$ In a study of breast asymmetry in women, as measured on mammography, the left breast was noted to be larger than the right in $55 \%$ of healthy women. ${ }^{1}$ Breast hypertrophy and development of breast cancer were reported to be more common on the left side. ${ }^{20}$ Breast asymmetry was also found to be greater in healthy women who subsequently developed breast cancer compared with those who did not develop breast malignancies. ${ }^{21}$ It has even been suggested that in individuals with a strong family history of breast cancer, any evidence of fluctuating bilateral breast asymmetry as seen on screening mammography may predict a risk of developing breast cancer. ${ }^{21}$ However, other studies have failed to find a correlation between breast size and cancer risk. ${ }^{9,22}$ In the present analysis, breast size or fluctuating bilateral breast asymmetry was not tested in relation to breast cancer laterality.

Breast feeding patterns have been considered as a possible explanation of breast cancer laterality. ${ }^{23}$ Lactation seems to have a modest protective effect on breast cancer. In a previous study of women in the Tanka or "boat" population of Hong Kong, who nurse their infants from one breast only, $27(79 \%)$ of 34 women with postmenopausally diagnosed breast cancer had tumors in the unused breast. ${ }^{24}$ It has been postulated that since right-handedness is more common in women, most mothers would use the left arm to support the baby they are feeding, and hence the left breast is used more often in lactation. However, making this assumption, the left breast should be afforded better protection against cancer, and not an increased incidence. ${ }^{7}$ Further, a predominance of left-sided breast cancer has also been reported in men. ${ }^{7}$

About $90 \%$ of the population is right-handed, and $97 \%$ of right-handed persons develop speech, language processing, and logic in the left hemisphere, the so-called "dominant" hemisphere. In contrast, the dominant hemisphere is located on the right side in $40 \%-50 \%$ of left-handed and ambidextrous individuals. ${ }^{25}$ Left-handedness is a surrogate for atypical ("reversed") brain asymmetry, reflecting, among 
other potential causes, intrauterine exposure to steroid hormones. ${ }^{26}$ Left-handedness has also been linked to other disorders, such as impaired cellular immunity, chromosomal abnormalities, and breast cancer at a relatively young age. ${ }^{27}$ Several previous studies have suggested that handedness was related ${ }^{10}$ or inversely related ${ }^{28}$ to breast cancer risk. Other studies have also evaluated handedness in relation to breast tumor laterality; their results, although inconclusive, suggest a correlation between left-handedness and tumors of the left breast. ${ }^{10}$ As personal handedness depends on various social, environmental, and developmental factors, normal or reversed brain asymmetry may be much more accurate in defining any developmental changes in relation to subsequent development of cancer. Indeed, radiological methods have shown that breast cancer subjects have a remarkably increased prevalence of reversed brain asymmetry compared with controls (49\% versus 18\%, respectively). Such studies support the hormone hypothesis for the etiology of breast cancer. ${ }^{25}$ Events in the prenatal and perinatal years could have an important bearing on carcinogenesis in the breast. ${ }^{20,29}$ Increased exposure of the female fetus to androgens would reduce the risk of developing breast cancer, while increased estrogen exposure would instead augment the risk of breast cancer, ${ }^{29}$ and possibly cerebral asymmetry. It has been previously suggested that the pattern of cerebral asymmetry and breast cancer risk may both be influenced by genes at chromosome locus 11q22-23. . $^{10,30}$ In the present study, breast cancer laterality was not related to handedness. However, the pattern of brain asymmetry in relation to breast cancer laterality was not tested.

A family history of breast cancer is an important risk factor for development of the disease. A family history has been associated with 2-3-fold increase in the risk of invasive as well as in situ breast cancer. ${ }^{31,32}$ Individuals with multiple first-degree family members diagnosed with ovarian cancer or breast cancer, particularly at a young age, are at even greater risk. ${ }^{31}$ This was evident in a study of 69 motherdaughter and sister-sister cases in London which reported a strong tendency toward concordance in sisters and a less strong but similar tendency in mothers and daughters. ${ }^{33}$ On the other hand, a study of 38 sister-sister cases at the University of Minnesota hospitals found no concordance regarding the side affected. ${ }^{24}$ In the present study, patients with a family history of breast cancer were usually younger in age, and were more likely to develop bilateral breast cancer, especially the metachronous type. There was a strong concordance between patients and their first-degree relatives in relation to breast cancer laterality, and this was highest between patients and their sisters (53.1\%), as well as between patients and their mothers (40.7\%). Furthermore, nearly one fifth of patients developed breast cancer at a similar age to their first-degree relatives (within 5 years), especially their sisters.

According to twin studies, most of the familial aggregation is explained by inherited susceptibility. ${ }^{24}$ It seems likely that there is a genetically influenced predisposition to breast cancer in the relatives of affected women. ${ }^{24}$ An association has been reported between inherited breast cancer and pathogenic alleles of genes involved in pathways critical for genomic integrity. ${ }^{34}$ Mutation in the high-penetrant genes BRCA-I and BRCA-II account for only $20 \%-25 \%$ of this inherited susceptibility. ${ }^{24}$ Other genes, such as the $p 53$ family of genes and phosphatase and tensin homologue (PTEN) confer a very high breast cancer risk associated with rare cancer syndromes. Mutation in checkpoint kinase 2 (CHEK2), ataxia telangiectasia mutated (ATM), Nijmegen breakage syndrome 1 (NBS1), RAD50, BRCA1-interacting protein 1 (BRIP1), and Partner and Localizer of BRCA2 (PALB2) are associated with at least a doubling of breast cancer risk. ${ }^{34}$ Other genetic variation with low-penetrance genes may substantially dictate breast cancer susceptibility. ${ }^{32}$ For example, the ADP-ribosylation factor-like tumor suppressor gene (ARLTS1), which is a member of the ADP-ribosylation factor family, has recently been identified as a tumor suppressor gene, playing a major role in provoking the attenuation of apoptotic functions. It is located on chromosome 13q14.3, a region frequently deleted in chronic lymphocytic leukemia and breast cancer. The ARLTS1 Trp149Stop gene mutation has been shown to predispose to general and high-risk familial breast cancers and to increase the risk of bilateral breast cancer. It is detected significantly more frequently in women from high-risk families than in controls. ${ }^{32}$

\section{Study limitations}

Being a retrospective analysis, this study has several limitations. The absolute number of patients was relatively small, so small differences, such as for the relationship between age and cancer laterality, were not statistically apparent. Incomplete information regarding family history in many patients may cast doubt on the validity of the conclusion reached. Such incomplete information was related to poor communication between some patients and their relatives, and inability to remember the relevant details concerning family members who died many years earlier. However, this study has significance despite those limitations. Its main strength is the inclusion of all consecutive breast cancer 
patients seen and followed closely in a single practice, ie, a real-world situation that offers a representative picture of cancer patients in general. Detailed family history was obtained by direct questioning of patients and their family members by the physician, aiming for detailed and accurate information. Extensive information regarding clinical presentation and tumor characteristics was investigated to identify possible factors that could explain clinical observations of laterality in breast cancer patients.

\section{Conclusion}

In this study, there was a preponderance of left-sided breast cancer in the patients seen, with a left to right ratio of 1.1. There were no significant differences between the two sides, particularly in regard to clinical presentation, tumor characteristics, or survival. However, when patients were compared with their first-degree relatives, there were significant similarities in cancer laterality, especially between patients and their sisters and mothers. There was also some evidence suggesting similarity for age at initial diagnosis of cancer.

It is possible that individuals with a strong family history of breast cancer are carriers of several inherited genetic mutations, which put them at greater risk of breast cancer. The risk is highest in carriers of high-penetrance genes such as $B R C A-I / I I$ or numerous low-penetrance genes, such as those listed above and possibly others. Inheritance of other genes may also contribute to the development of spatial laterality, with or without cerebral asymmetry, before and during gastrulation. Inherited genetic susceptibility with hormonal exposure during gastrulation may lead to initiation of breast cancer in utero. After many years of development, growth, and progression, breast cancer may subsequently present at a relatively similar age and with the same cancer laterality. Obviously, such a hypothesis needs further study to confirm or refute its validity. If confirmed, it may have a major impact with regard to earlier diagnosis of breast cancer and its subsequent management.

\section{Acknowledgments}

The author thanks the following physicians: Joseph Anigbogu, Kemi Azeez, Pratap Balusu, Glenn Bryant, Sreenivasa Chanamolu, Henry Gerad, Ravi Kamepalli, Abbas Khalil, Robert Keighley, Sarat Kuchipudi, Chaoyang Li, Oluremi Ojo, David Powell, and Abdullah Taja for patient referrals.

\section{Disclosure}

The author reports no conflicts of interest in this work.

\section{References}

1. Senie RT, Rosen PP, Lesser ML, Snyder RE, Schottenfeld D, Duthie K. Epidemiology of breast carcinoma II: factors related to the predominance of left-sided disease. Cancer. 1980;46(7):1705-1713.

2. Ekbom A, Adami HO, Trichopoulos D, Lambe M, Hsieh CC, Ponten J. Epidemiologic correlates of breast cancer laterality (Sweden). Cancer Causes Control. 1994;5(6):510-516.

3. Kamby C, Andersen J, Ejlertsen B, et al. Pattern of spread and progression in relation to the characteristics of the primary tumour in human breast cancer. Acta Oncol. 1991;30(3):301-308.

4. von Fellenberg R. Schweiz. Erhebung fiber maligne Tumoren [Switzerland. Survey of malignant tumors]. Bull Eidgenoss Gesundheitsamt, Bern. 1940. German.

5. Edge S, Byrd DR, Compton CC, Fritz AG, Greene, FL, Trotti, A, editors. American Joint Committee of Cancer Staging Manual. 7th ed. New York: Springer Adis US, LLC; 2010.

6. Roychoudhuri R, Putcha V, Moller H. Cancer and laterality: a study of the five major paired organs (UK). Cancer Causes Control. 2006;17(5): $655-662$.

7. Wilting J, Hagedorn M. Left-right asymmetry in embryonic development and breast cancer: common molecular determinants? Curr Med Chem. 2011;18(36):5519-5527.

8. Weiss HA, Devesa SS, Brinton LA. Laterality of breast cancer in the United States. Cancer Causes Control. 1996;7(5):539-543.

9. Perkins CI, Hotes J, Kohler BA, Howe HL. Association between breast cancer laterality and tumor location, United States,1994-1998. Cancer Causes Control. 2004;15(7):637-645.

10. Titus-Ernstoff L, Newcomb PA, Egan KM, et al. Left-handedness in relation to breast cancer risk in postmenopausal women. Epidemiology. 2000;11(2):181-184.

11. Woodward WA, Strom EA, McNeese MD, et al. Cardiovascular death and second non-breast cancer malignancy after postmastectomy radiation and doxorubicin-based chemotherapy. Int J Radiat Oncol Biol Phys. 2003;57(2):327-335.

12. Kollias J, Ellis IO, Elston CW, Blamey RW. Prognostic significance of synchronous and metachronous bilateral breast cancer. World J Surg. 2001;25(9):1117-1124.

13. Awad AT, el-Husseini G, Anwar M, Abu-Nasr A, Anwar AA, Sakr M. Bilateral primary breast cancers: a clinicopathological study of the second primary. Int Surg. 1996;81(1):57-60.

14. Yerushalmi R, Kennecke H, Woods R, Olivotto IA, Speers C, Gelmon KA. Does multicentric/multifocal breast cancer differ from unifocal breast cancer? An analysis of survival and contralateral breast cancer incidence. Breast Cancer Res Treat. 2009;117(2):365-370.

15. Haque R, Yood MU, Geiger AM, et al. Long-term safety of radiotherapy and breast cancer laterality in older survivors. Cancer Epidemiol Biomarkers Prev. 2011;20(10):2120-2126.

16. Jagsi R, Griffith KA, Koelling T, Roberts R, Pierce LJ. Rates of myocardial infarction and coronary artery disease and risk factors in patients treated with radiation therapy for early-stage breast cancer. Cancer. 2007;109(4):650-657.

17. Correa CR, Litt HI, Hwang WT, Ferrari VA, Solin LJ, Harris EE. Coronary artery findings after left-sided compared with right-sided radiation treatment for early-stage breast cancer. J Clin Oncol. 2007;25(21):3031-3037.

18. Soerjomataram I, Louwman MW, Ribot JG, Roukema JA, Coebergh JW. An overview of prognostic factors for long-term survivors of breast cancer. Breast Cancer Res Treat. 2008;107(3):309-330.

19. Holmberg L, Adami HO, Ekbom A, Bergstrom R, Sandstrom A, Lindgren A. Prognosis in bilateral breast cancer. Effects of time interval between first and second primary tumours. $\mathrm{Br}$ J Cancer. 1988;58(2):191-194.

20. Olsson H, Ingvar C. Left handedness is uncommon in breast cancer patients. Eur J Cancer. 1991;27(12):1694-1695.

21. Scutt D, Lancaster GA, Manning JT. Breast asymmetry and predisposition to breast cancer. Breast Cancer Res. 2006;8(2):R14. 
22. Trichopoulos D, Lipman RD. Mammary gland mass and breast cancer risk. Epidemiology. 1992;3(6):523-526.

23. Ing R, Petrakis NL, Ho JH. Unilateral breast-feeding and breast cancer. Lancet. 1977;2(8029):124-127.

24. King MC, Lynch HT, Selvin S. Laterality of breast cancer in families. Am J Epidemiol. 1979;110(1):88-98.

25. Klar AJ. Breast cancer predisposition and brain hemispheric laterality specification likely share a common genetic cause. Breast Dis. 2011; 33(1):49-52.

26. Geschwind N, Galaburda AM. Cerebral lateralization. Biological mechanisms, associations, and pathology: II. A hypothesis and a program for research. Arch Neurol. 1985;42(6):521-552.

27. London WP. Left-handedness and life expectancy. Percept Mot Skills. 1989;68(3 Pt 2):1040-1042.

28. Stellman SD, Wynder EL, DeRose DJ, Muscat JE. The epidemiology of left-handedness in a hospital population. Ann Epidemiol. 1997;7(3): $167-171$.
29. Trichopoulos D. Hypothesis: does breast cancer originate in utero? Lancet. 1990;335(8695):939-940.

30. London WP. Reversed cerebral asymmetry and breast cancer. Lancet. 1992;339(8800):1055-1056.

31. Claus EB, Stowe M, Carter D. Family history of breast and ovarian cancer and the risk of breast carcinoma in situ. Breast Cancer Res Treat. 2003;78(1):7-15.

32. Frank B, Hemminki K, Meindl A, et al. Association of the ARLTS1 Cys148Arg variant with familial breast cancer risk. Int $J$ Cancer. 2006;118(10):2505-2508.

33. Penrose LS, Mackenzie HJ, Karn MN. A genetical study of human mammary cancer. Br J Cancer. 1948;2(2):168-176.

34. Cardis E, Hall J, Tavtigian SV. Identification of women with an increased risk of developing radiation-induced breast cancer. Breast Cancer Res 2007;9(3):106.
Cancer Management and Research

\section{Publish your work in this journal}

Cancer Management and Research is an international, peer-reviewed open access journal focusing on cancer research and the optimal use of preventative and integrated treatment interventions to achieve improved outcomes, enhanced survival and quality of life for the cancer patient The journal welcomes original research, clinical \& epidemiological

\section{Dovepress}

studies, reviews \& evaluations, guidelines, expert opinion \& commentary, case reports \& extended reports. The manuscript management system is completely online and includes a very quick and fair peerreview system, which is all easy to use. Visit http://www.dovepress.com/ testimonials.php to read real quotes from published authors.

Submit your manuscript here: http://www.dovepress.com/cancer-management-and-research-journal 